\title{
Source: a water resource modelling system for supply augmentation planning
}

\author{
Ashok K. Raut, Richa Neupane, Golam Kibria and Mahes S. Maheswaran \\ WaterNSW, Parramatta, Sydney, Australia \\ Email: Ashok.Raut@,WaterNSW.com.au
}

\begin{abstract}
Water sharing and management plans and policies in Australia have long been supported by the analytical capabilities of water balance simulation models. The ability of these models to assess the likely outcomes of various policy scenarios inform stakeholders to decide on acceptable or optimal settings. WaterNSW has recently developed water resources planning models for all regulated basins in NSW including the Border Rivers Basin, where WaterNSW has responsibility of bulk water supply.

The Border Rivers is a complex water resource system with several major rivers and tributaries and head storages. The resource is shared between two states - NSW and Queensland. The current supply reliability of the system has been less than 50\% and this is worse in the recent drought years. In 2019, NSW and Federal government jointly announced a proposal of Critical State Significant Infrastructure (CSSI) program that include three dams in the Northern NSW valleys including a new dam on the Mole River. This paper aims to demonstrate the application of SOURCE to evaluate the NSW's decision of constructing a new storage on one of the major unregulated tributaries such as the Mole River Dam as a supply augmentation option.

A calibrated daily baseline SOURCE model has been developed for the Border Rivers Basin and the Mole River Dam has been configured with the necessary changes in the resource assessment of NSW that is expected to have its $100 \%$ ownership. The model is run from 1911 to 2016 to calculate the relevant modelling outputs such as regulated release, effective allocation, and so on for various Mole River Dam storage sizes such as 50,100,150, and $200 \mathrm{GL}$. These modelling outputs can be converted into economic terms to calculate the project benefits. These benefits can be compared with the project costs to calculate the return on the investment. It is thus clear that SOURCE can be used as a water resource modelling system tool for supply augmentation planning.
\end{abstract}

Keywords: Border Rivers, SOURCE, Mole River, Macintyre, Dumerisq 


\section{INTRODUCTION}

Water sharing and management plans and policies in Australia have long been supported by the analytical capabilities of water balance simulation models (NOW, 2013). The ability of these models to assess the likely outcomes of various policy scenarios inform stakeholders to decide on acceptable or optimal settings.

Recent Water Reforms intended to provide more water for the environment, and water quality management. These required the analysis of more complex water management arrangements and a water quality modelling capability. These changes required more model complexity, where representing the short-term flow variability became increasingly more important.

WaterNSW has recently developed water resources planning models for all regulated basins in NSW including the Border Rivers Basin, where WaterNSW has responsibility of bulk water supply. The planning models will enable WaterNSW to assess the level of services and undertake the future infrastructure option investigations. A water resources system planning model is a water balance model, which quantifies the movement of water within the system under the natural and man-made conditions and rules. WaterNSW has selected the eWater SOURCE as modelling platform for the development of planning models.

Underpinned by world-class science and technical innovation, SOURCE is a complete state-of-the-art water resource system modelling tool (eWater SOURCE). As a daily time-step model with planning, operations and forecasting modes, it can be used for all aspects of water resource management, including:

- water balance studies from catchment to river basin scale

- $\quad$ analysis of supply and demand balances, including agricultural, hydropower, urban, industrial, and environmental demands

- water quality analysis based on catchment land-use scenarios

- reservoir and river operations, encompassing low to high flow events, salt loads and system optimisation

- urban water system planning, operations, and optimisation, including analysis of different supply options (reservoir/recycling/desalination)

- climate change adaptation analyses

- groundwater-surface interactions.

This study describe how Source can be used for planning supply augmentation of a water resource system. This capability of SOURCE is explained through a real-life example of a complex water resource system like the Border Rivers Basin. Note that the aim of this study is only to demonstrate the application of SOURCE.

\section{AIM OF THE STUDY}

The Border Rivers is a complex water resource system with several major rivers and tributaries and head storages. The resource is shared between two states - NSW and Queensland. The current supply reliability of the system has been less than 50\% and this is worse in the recent drought years. In 2019, NSW and Federal government jointly announced a proposal of Critical State Significant Infrastructure (CSSI) program that include three dams in the Northern NSW valleys including a new dam on the Mole River. This paper aims to demonstrate the application of SOURCE to evaluate the NSW's decision of constructing a new storage on one of the major unregulated tributaries such as the Mole River Dam as a supply augmentation option. The analyses would attempt to answer the following questions but not limited to:

- How big would be the new storage?

- How much more regulated water would be available?

- How much would the supply reliability improve?

\section{OVERVIEW OF THE BORDER RIVERS BASIN}

\subsection{Basin Catchment}

The Border Rivers catchment is located at the western side of the Great Dividing Range. It has a total area of about 48,600 sq km and lies, in approximately equal sections, in Northern NSW and Southern QLD (Figure 1). The major streams of the basin are the Macintyre and Severn Rivers in the South-East, the Dumaresq River in the East, and Macintyre Brook and the Weir River in the North and North-West. With the exemption of the Weir River, these main rivers are regulated with a major dam located upstream of each catchment. 
There are several flood runners and anabranches that break out at various levels throughout the system. The upper part of the entire catchment to the east is in the Great Dividing Range and has steep topography and high relief. This grades into undulating hills, and gradually flattens towards the West around Boggabilla. The elevation ranges around $1500 \mathrm{~m}$ in the East in the Great Dividing Range to $150 \mathrm{~m}$ in the West around Mungindi.

\subsection{Climate}

The rainfall pattern is almost unimodal with the summer months having most rainfall. Almost conforming with the topography of the basin with higher elevation having higher rainfall, its spatial distribution varies from the highest in the Great Dividing Range in the East to the lowest in the West with the annual average of up to $1100 \mathrm{~mm}$ to $550 \mathrm{~mm}$ respectively (Figure 1). This information is based on daily gridded BoM rainfall data over the Border Rivers catchment from 1911 to 2016. In contrast, the evapotranspiration pattern is opposite to that of the rainfall having highest in the West and the lowest in the East. For this reason, high rainfall and low evapotranspiration in the East generates more runoff than the plain in the West, where there is high evapotranspiration and low rainfall.

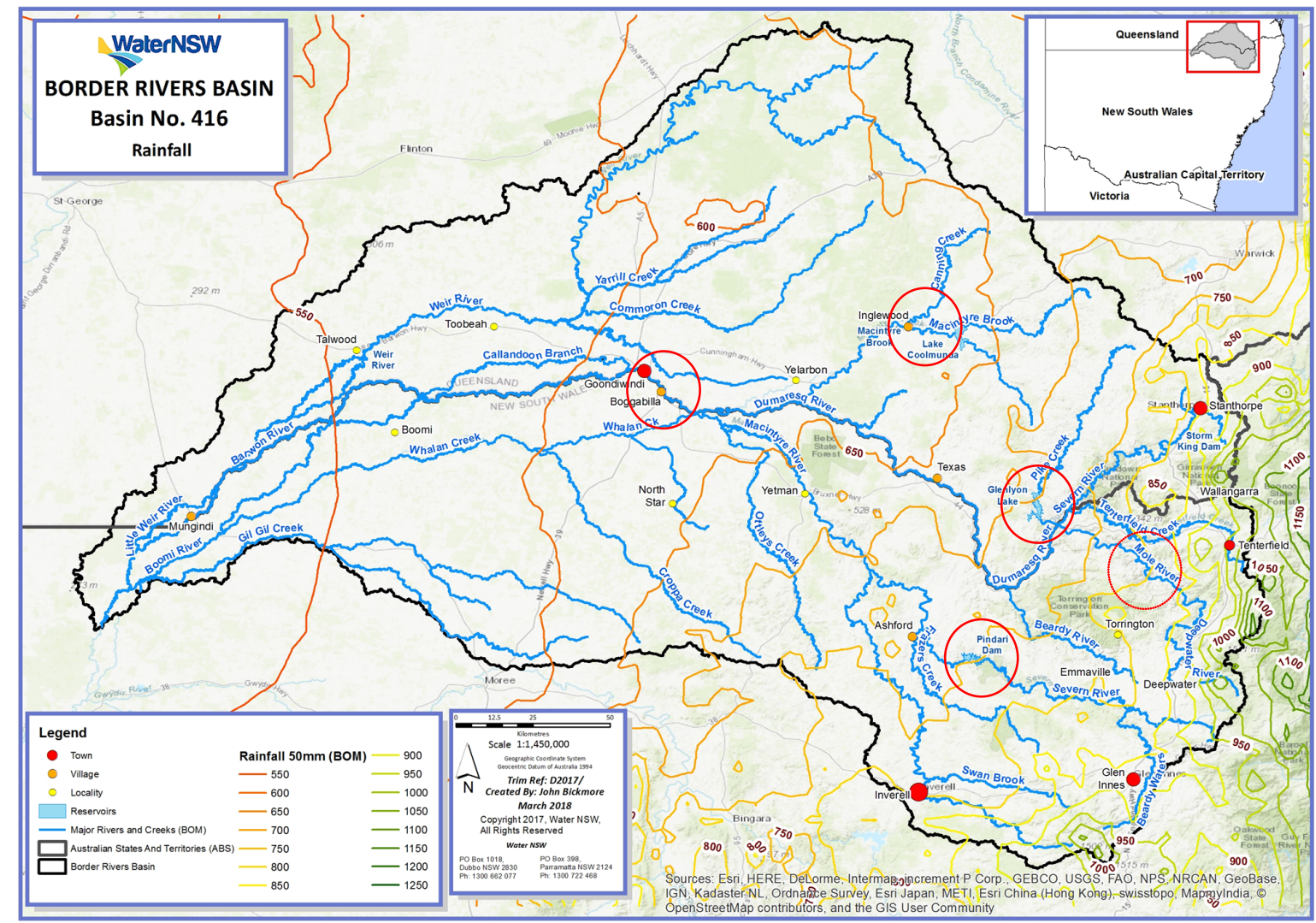

Figure 1. Border Rivers Basin rainfall pattern

\subsection{Agriculture}

Maximum irrigable area in the regulated catchment of the Border Rivers Basin is about 40,000 ha in NSW and 50,000 ha in QLD. Normally, the crops grown in the basin are Cotton, Lucerne, Pasture, Cereals Horticulture and Peanut. Cotton is the dominant crop in the recent time with about 80 to $90 \%$ coverage (Figure 2) 

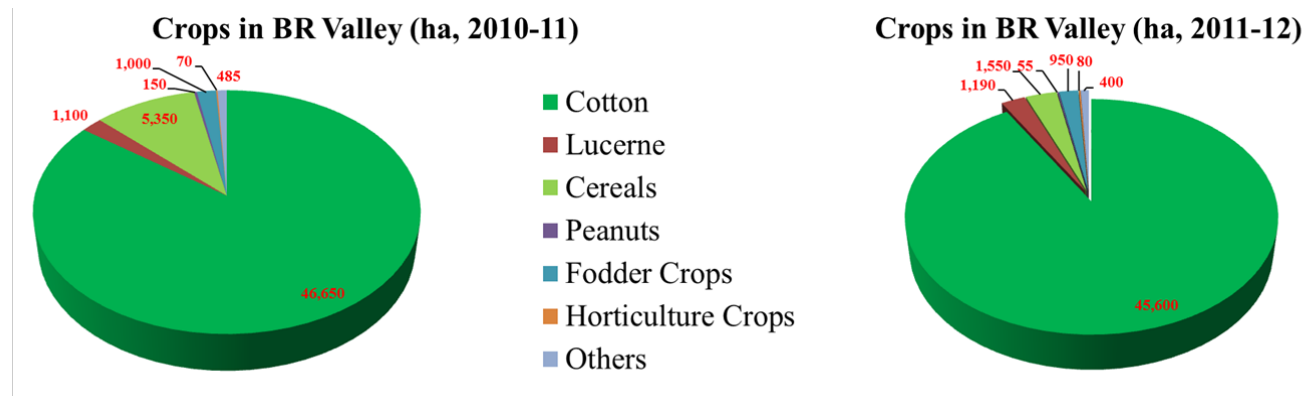

Figure 2. Typical crop coverage in the Border River Basin (Border Rivers Commission)

\subsection{Existing Supply Storages}

The major existing supply storages in the regulated part of the basin are:

- Pindari, 312 GL (100\% NSW)

- Glenlyon, 254 GL (57\% NSW, $43 \%$ QLD)

- Coolmunda, 69 GL (100\% QLD) and

- Boggabilla, 5.8 GL (57\% NSW, 43\% QLD)

Boggabilla Storage is a regulating weir that regulates the unregulated inflow from upstream tributaries and during the irrigation season, it stores the regulated water released in advance to meet the expected downstream water orders relatively quickly. Apart from these storages, a new storage on the Mole River (Figure 1) has been proposed under the CSSI projects.

\subsection{Basin Water Sharing Rules}

The basin water is shared between the states and among the state licence holders of different categories mainly according to the following but not limited to:

- Water Sharing Plan for the NSW Border Rivers Regulated River Water Source 2009 (NSW Border Rivers Water Sharing Plan, WSP)

- QLD Border Rivers Resource Operations Plan 2008 (QLD Border Rivers Resource Operation Plan, $\underline{\mathrm{ROP}})$

- New South Wales - Queensland Border Rivers Intergovernmental Agreement 2008 (NSW-QLD Intergovernmental Agreement, IGA)

- Dumaresq-Barwon Border Rivers Commission Standing Operating Procedure (SOP) for Continuous Accounting of the States Shares of the Inflows to Glenlyon Dam and the Border Rivers Regulated Flows

- Boggabilla Weir Standard Operating Procedure (SOP)

As the Border Rivers Basin is a shared resource between NSW and QLD, all rules associated with the resource is detailed in these documents. The resource of each state has been allocated to different users within the state. The users have access licence with different level of allocation priorities such as high security, stock and domestic, general security, and supplementary. The planned environmental water reserve and releases for each storage including the maximum long-term diversion limit for the basin are also outlined in these documents.

\subsection{Water Accounting System}

SOURCE supports various water accounting systems normally prevalent in the Murray Darling Basin water accounting - annual, continuous, and continuous sharing. Details about the accounting systems can be found in the SOURCE documentation at the eWater website (Water Accounting Systems). The regulated Border Rivers operates under a continuous accounting system and dam wall debiting. The Border Rivers regulated part includes Pindari and Glenlyon Storages and downstream river reaches up to Mungindi. Coolmunda System operates under Continuous Sharing system.

\subsection{Resources Sharing in the Basin}

Inflow into Glenlyon Storage is shared between NSW and QLD in proportion of 57:43 respectively including all tributary inflows in the regulated part. 


\subsection{Baseline Model Setup and Calibration}

A daily baseline model has been configured based on the sub-catchments determined by the river gauges having significant flow data, and the river gauges defining the regulated river reaches. All water access entitlements of different categories have been consolidated based on the river reaches. The resource assessments have been configured for QLD continuous accounting for Glenlyon and QLD continuous sharing accounting for Coolmunda and NSW Pindari and Glenlyon. The baseline model has been calibrated at various stages against observed data:

- Headwater catchment rainfall-runoff model against the observed gauge flow

- Storage catchment rainfall-runoff model against the back-calculated storage flow

- Regulated river reach calibration for storage routing and losses with historic diversions against the observed gauge flow

- On- and off (supplementary) - allocation diversion

- Irrigation demand model against the historic diversions (on- and off- allocation)

- Planted area against the historic planted area and

- End-of-System flow against the observed flow at the basin outlet.

At the junction of the Macintyre River and Dumerisq River, the downstream NSW water orders are sent to the upstream storages such as Glenlyon and Pindari in a way that minimises the chance of storage spills. The baseline model has been calibrated against the observed data in the recent time. The catchment rainfall-runoff models have been calibrated relatively with relatively longer period data, whereas the storage simulation calibration with shorter period data since adequate historic diversion and other data are not available at the spatial and temporal scale of the model. Some of the calibration plots are given for reference (Figure 3 and Figure 4). The discrepancy in the Pindari storage behaviour is most likely because the operators at times use their discretion against the relevant SOP's while choosing the storage for a particular downstream order. Sometimes, the QLD orders are released from Pindari storage with the NSW orders to minimise the delivery loss, particularly when the QLD orders are small.

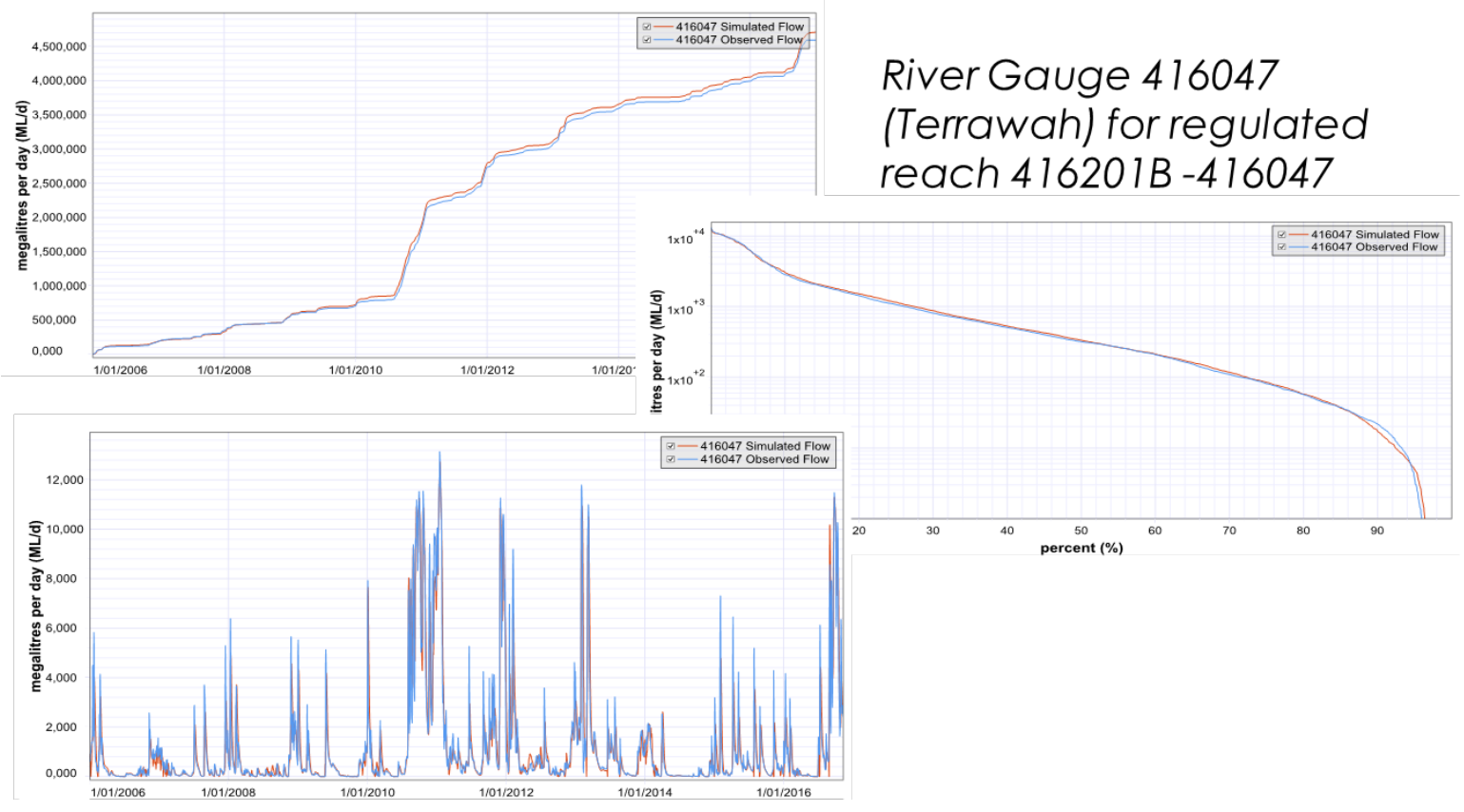

Figure 3. Storage routing calibration for one of the regulated river reaches 


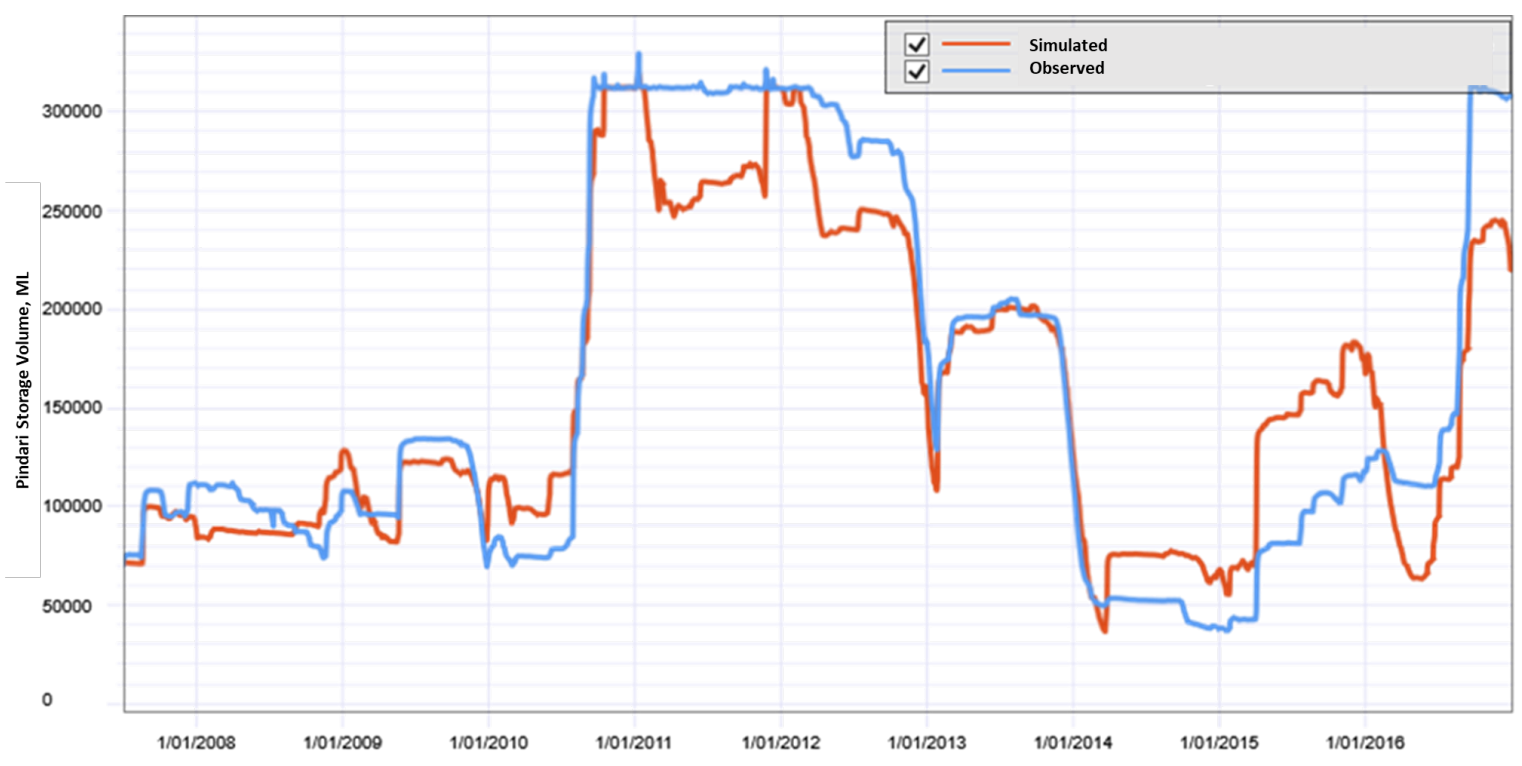

Figure 4. Pindari storage behaviour during calibration period

\section{PROPOSED SUPPLY AUGMENTATION OPTION}

A dam on the Mole River (Figure 1) has been proposed under the NSW government's CSSI program to enhance the supply reliability in the basin. The location was taken from the WaterNSW's 20-year Infrastructure Strategy study report. All topography information around the dam site such as Area-Elevation-Storage rating has been derived from the high resolution lidar survey data. A new Mole River Dam was configured on the calibrated baseline model with the Mole River Dam as $100 \%$ NSW asset as an addition to NSW resource. The long-term average inflow at the dam has been calculated from the catchment model and is about $70 \mathrm{GL} /$ year. A range of storage sizes for the dam were evaluated in terms of relevant modelling outputs such as regulated release,

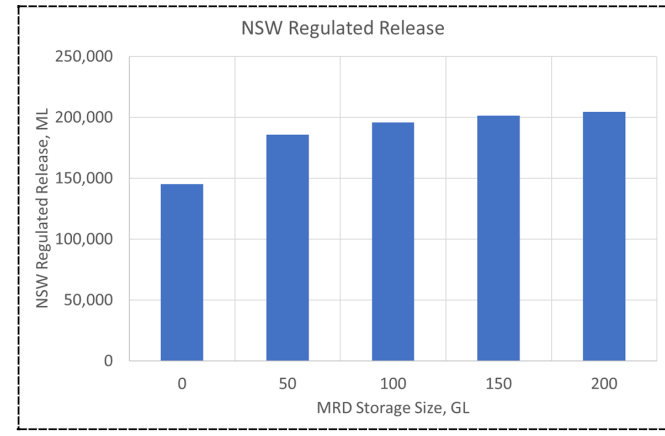

Figure 5. NSW regulated releases for different MRD storage sizes effective allocation, etc. As the environmental water release rules have not yet been decided, a hypothetical environmental release in proportion to the catchment area of Pindari storage has been considered for initial analyses. For reference, some of the outputs are given in Figure 5 and Figure 6 for 50 GL, 100 GL, 150 GL and 200 GL storage sizes.

\section{DISCUSSION AND CONCLUSION}

The modelling outputs such as regulated release and effective allocation shown in Figure 5 and Figure 6 clearly demonstrate that they increase with storage sizes. Nevertheless, the rate of increment gradually decreases to a point where the increment is negligible. There could be several more such modelling outputs of the project interests. This shows that the resource is limited. Normally, while carrying out the project costbenefit analyses, these outputs are transformed into economic terms using the accepted methodology and compared with incremental costs to determine the optimal storage size that gives the highest return on the investment.

This study clearly shows that SOURCE can be used for the supply augmentation planning in a complex basin like the Border Rivers. 


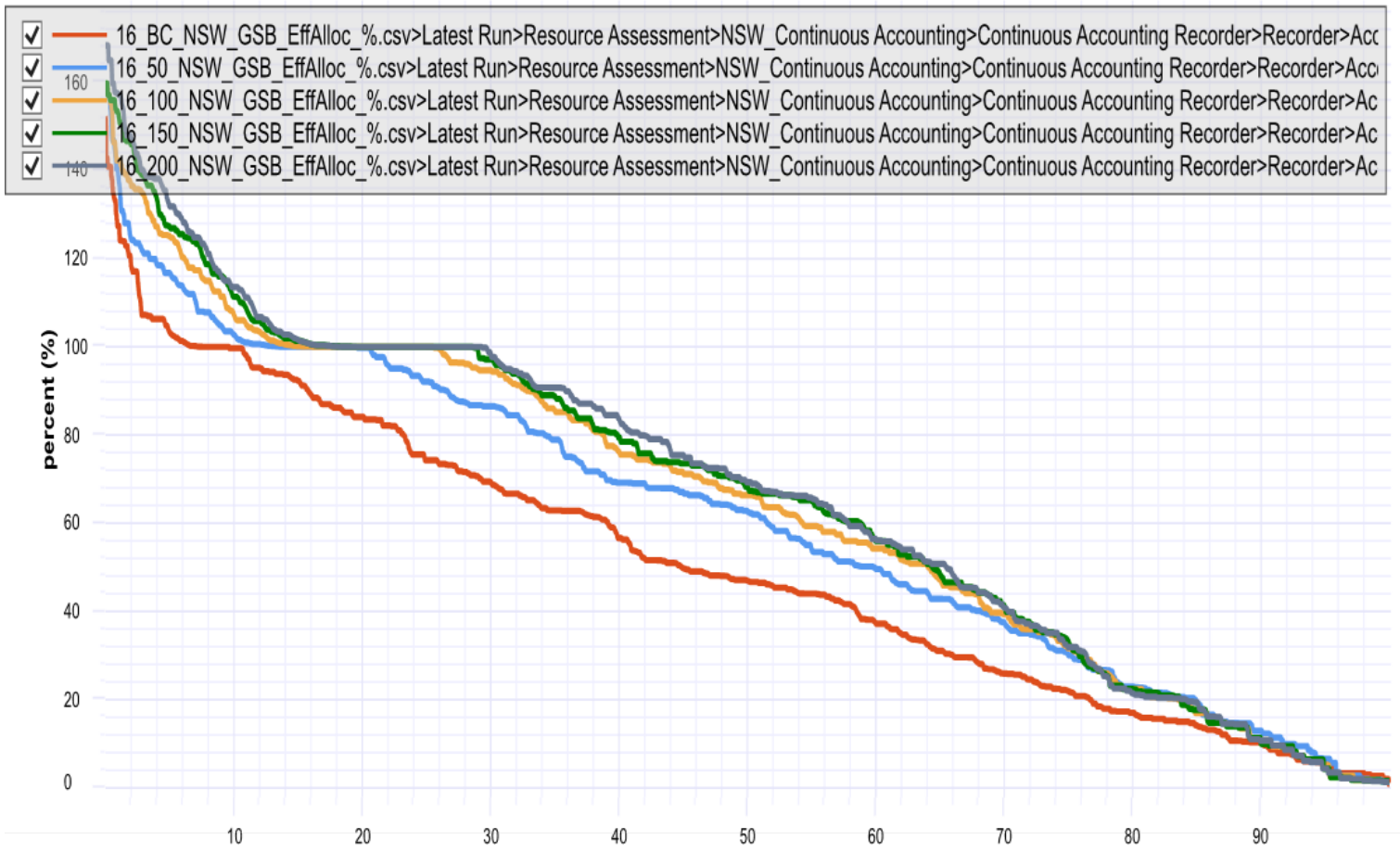

Figure 6. Effective allocation for base case and MRD storage sizes of 50 GL, 100 GL, 150 GL and 200 GL

\section{ACKNOWLEDGEMENT}

The authors acknowledge the support of our operation team in Goondiwindi for their support by taking an exploratory tour of the basin including the dam sites to familiarise with the catchment and operating rules.

\section{REFERENCES}

eWater Source. https://ewater.org.au/products/ewater-source/

New South Wales - Queensland Border Rivers Intergovernmental Agreement 2008

https://www.resources.qld.gov.au/_data/assets/pdf file/0006/105963/intergovernment-agreement.pdf

QLD Border Rivers Resource Operations Plan 2008

https://www.accc.gov.au/system/files/Sub\%20\%234\%20Sun\%20Water\%20(attachment\%201) 0.pdf

Sivkova, M., O’Neill, R. and Beecham, R., 2013. Border Rivers Valley: IQQM Cap Implementation Report, NSW Department of Primary Industries, Office of Water, Australia

Water Sharing Plan for the NSW Border Rivers Regulated River Water Source 2009.

https://legislation.nsw.gov.au/view/html/inforce/current/sl-2009-0218 